\title{
Predicting the results of rhinoplasty before surgery: Easy noses versus difficult noses
}

\author{
Nabil Fanous MD FRCSC ${ }^{1}$, Valérie Julie Brousseau MDCM², Naznin Karsan MD FRCSC ${ }^{2}$, Amanda Fanous $^{3}$
}

N Fanous, VJ Brousseau, N Karsan, A Fanous. Predicting the results of rhinoplasty before surgery: Easy noses versus difficult noses. Can J Plast Surg 2008;16(2):69-75.

A major problem for many rhinoplastic surgeons is the ability to predict, before surgery, the difficulty of the procedure (whether the rhinoplasties will be technically easy or technically difficult to perform) and the success rate of the result (whether the rhinoplasty will likely give good results or poor ones).

The present paper outlines a systematic approach to nasal analysis, allowing the surgeon to consistently estimate, before surgery, the degree of technical difficulty of each rhinoplasty, as well as predicting its future result in terms of patient satisfaction. This preoperative evaluation is based on the analysis of the skin texture and the osteocartilagenous framework on lateral and frontal views. It allows for the nose to be classified as green (easy), yellow (moderate) or red (difficult), depending on two factors: the degree of surgical difficulty and the expected patient's satisfaction with the result.

The essence of the present paper is to introduce a simple, systematic approach to assist the novice rhinoplastic surgeon to assess the complexity, the risks and the expected outcome of a rhinoplasty in the preoperative period, rather than postoperatively.

\section{Prédiction préopératoire de l'issue de la rhinoplastie : $\mathrm{Nez}$ faciles vs difficiles}

\begin{abstract}
L'un des problèmes majeurs pour de nombreux chirurgiens rhinoplasticiens est leur capacité de prédire la difficulté de l'intervention avant la chirurgie (la rhinoplastie sera-t-elle facile ou difficile sur le plan technique?) et son taux de succès (la rhinoplastie donnera-t-elle de bons ou de mauvais résultats?).

Le présent article décrit de manière succincte une approche systématique pour l'analyse du nez. Elle permet au chirurgien d'estimer de manière objective avant la chirurgie le degré de difficulté technique de chaque rhinoplastie et de prédire ainsi la satisfaction des patients. Cette évaluation préopératoire se fonde sur une analyse de la texture de la peau et des structures ostéocartilagineuses latérales et frontales. Elle permet de classifier les rhinoplasties en catégories assorties d'un code couleur : vert (faciles), jaune (modérées) ou rouge (difficiles) selon deux paramètres, soit degré de difficulté chirurgicale et satisfaction escomptée du patient vis-à-vis des résultats. Le but du présent article est d'expliquer une approche simple et systématique pour aider le chirurgien rhinoplasticien peu expérimenté à évaluer la complexité, les risques et l'issue escomptée d'une rhinoplastie à la phase préopératoire plutôt que post-opératoire.
\end{abstract}

Key Words: Difficult; Easy; Predicting results; Rhinoplasty

Several publications have sought to define the psychological profile of the ideal candidate for rhinoplasty $(1-6)$ and the different techniques associated with rhinoplasty (7-22). However, there is no literature addressing preoperative prediction of the technical difficulty and the associated outcome of a rhinoplasty.

While some surgeons tend to consider all rhinoplasties as simple and rewarding procedures, others view them all as technically challenging, complex and unpredictable. The truth lies between the two opinions: some rhinoplasties are technically easy to perform (from the surgeon's perspective) and tend to give impressive results (from the patient's point of view), whereas others are difficult to perform (from the surgeon's perspective) and lead to 'unimpressive' results (from the patient's point of view).

As rhinoplastic surgeons gain experience, they become more comfortable with the technical aspects of the surgery and better equipped to predict its probable outcome at the time of the preoperative assessment. However, for novice surgeons starting their rhinoplasty practice, or surgeons who do not perform a large volume of nasal surgeries, predicting the complexity and results of their rhinoplasties may present a significant challenge.
We propose a simple, systematic approach to the preoperative assessment of the rhinoplastic patient to predict which noses are technically easy or difficult to handle intraoperatively, and which will have a perceived good or suboptimal aesthetic result postoperatively.

We believe that the proper evaluation of the expected complexity of a rhinoplasty, as well as the ability to predict postoperative results preoperatively, are an essential part of the rhinoplastic surgeon's training. Indeed, the ability to predict satisfaction and results preoperatively may have a significant impact on overall patient satisfaction, referral pattern and, ultimately, the success of a practice.

\section{Classification}

\section{METHODS}

The preoperative evaluation of a rhinoplasty is simplified by dividing noses into three groups (Figure 1).

The first group, called 'green light noses', includes noses that are reasonably easy to operate from the surgeon's point of view, and where good results, from the patient's perspective, are easily achieved.

These noses are ideal for the occasional or beginner rhinoplastic surgeon. In addition to requiring minimal to moderate

${ }^{1}$ Canadian Institute of Cosmetic Surgery, Westmount, Montréal; ${ }^{2}$ Department of Otolaryngology - Head and Neck Surgery, McGill University;

${ }^{3}$ Medical School, McGill University, Montréal, Québec

Correspondence: Dr Nabil Fanous, 1 Westmount Square, Suite 1380, Westmount, Montréal, Québec H3Z 2P9. Telephone 514-935-9906,

fax 514-935-6482, e-mail cosmeticsurgery123@videotron.ca 


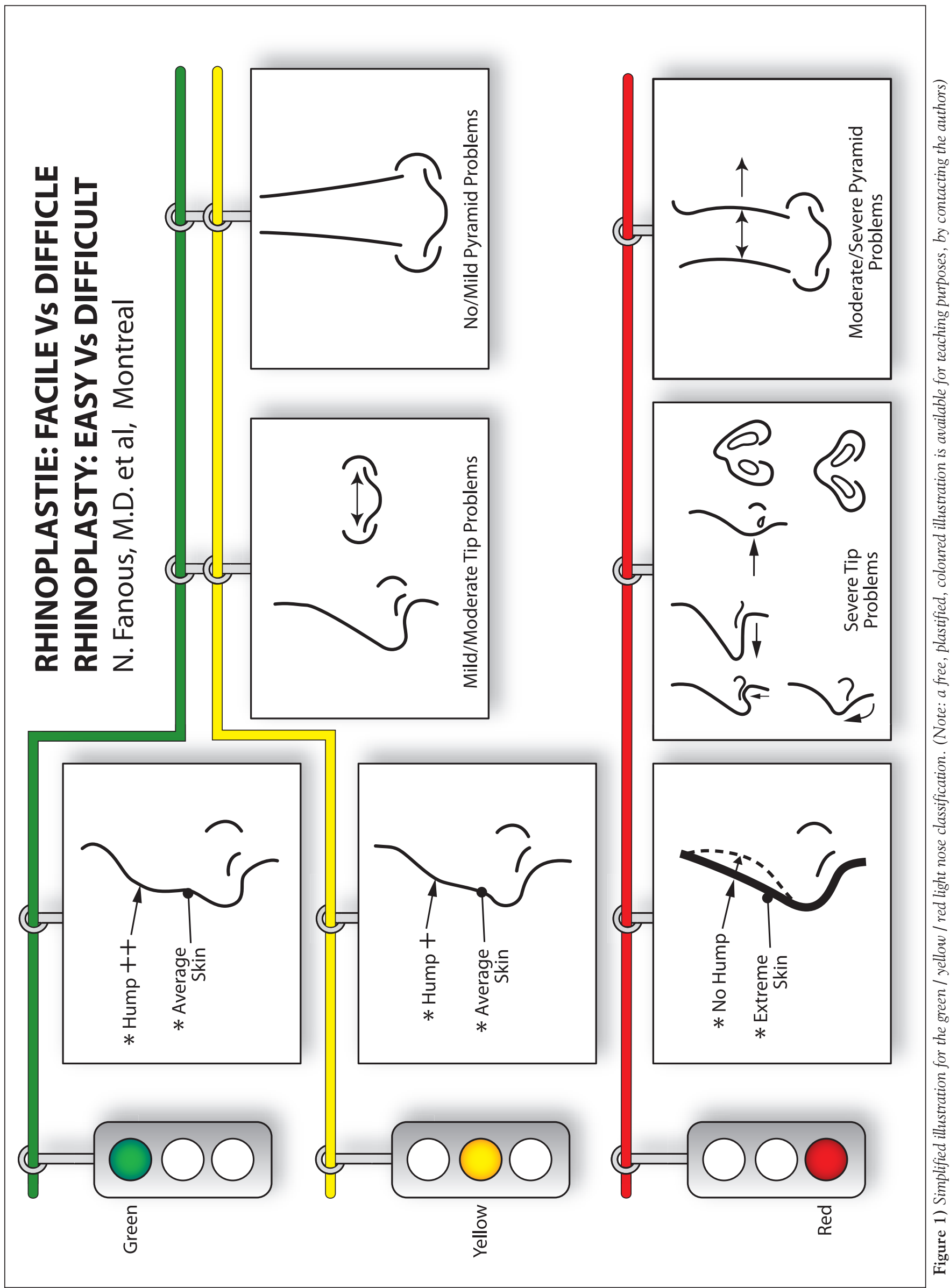


experience, they also usually lead to satisfied patients and bolster the surgeon's reputation.

The second group, called 'yellow light noses', ranges between the 'green' and 'red' groups.

The third group, called 'red light noses', includes noses that are difficult to operate from the surgeon's point of view, and are likely to give limited results from the patient's point of view.

Only highly experienced rhinoplastic surgeons should attempt to correct these noses, because the main reward may end up being the surgeon's self-satisfaction for tackling a challenging job.

\section{DIAGNOSIS}

For simplicity, the three most important criteria that determine nose classification are, in order of priority, the profile view (the most crucial evaluating factor), the skin thickness and the frontal view.

Analysis of the profile view should be performed first, followed by skin palpation and frontal view analysis.

Once this initial assessment is performed, the patient is categorized as having a green light, yellow light or red light nose (Figure 1).

\section{THE THREE NASAL CATEGORIES}

\section{Red light (Figure 1)}

Noses in the red light category have one or more major problems related to the profile view, skin thickness or frontal view. Major problems are problems that will make the execution of the surgery very challenging and, even when well performed, will tend to produce results that are unlikely to impress patients or their relatives.

Profile view: A major problem in the profile view of a red light nose is the absence of any hump. This has two implications: first, the surgery will not produce the impressive result achieved with a large hump removal; second, in the absence of a prominent dorsum, the patient's motivation to undergo rhinoplasty is usually due to other factors, such as a recessed dorsum (saddle deformity), an important tip deformity or a pyramid deviation, all of which are much harder to correct. Furthermore, the results of such corrections are relatively unimpressive to the layperson, in spite of the high level of surgical skill and experience required.

Skin thickness: A major problem pertaining to skin consists of very thick or, infrequently, very thin skin. Very thick skin has poor contractibility and may not shrink enough after bony or cartilaginous resection. In other words, the nose with a thick skin can not be made much smaller, because reducing the internal nasal structures (such as cartilage and bone) may not be accompanied by enough contraction of the external skin envelope covering them.

On the other hand, very thin skin has excellent contractibility but poor buttressing and camouflaging capacity. In particular, thin skin is unable to hide minor bony or cartilaginous irregularities, which tend to be accentuated postoperatively, after the major part of the surgically induced edema dissipates with time.

Frontal view: In the frontal view, major problems may be detected at the tip or the nasal pyramid areas of the red light nose.

Tips presenting a major problem are those that are very wide, very asymmetric, very prominent, very recessed, or overturned down or up, etc. Such deformities are challenging to correct, even in experienced hands, and the results they generate are usually more gratifying to the surgeon than to the patient. It should be emphasized that patients requesting correction of these types of tips tend to be critical of even mild imperfections and rarely appreciate the complexity of such surgery.

A major problem at the level of the pyramid usually relates to such issues as its straightness or width, including side-to-side deviation, S-type deviation, or a very wide or very thin bridge. Again, analysis and correction of a major pyramid deformity is a complex task with relatively unpredictable outcomes. Here too, patients tend to be less appreciative and more critical of results.

Hence, any one of the major problems described above is enough in itself to classify the nose as 'red light', regardless of the other nasal elements. Figure 2 shows examples of red light noses.

\section{Green light (Figure 1)}

Profile view: Noses in the green light category must have one specific feature on the profile view: a large dorsal hump. Removal of a large hump, which is technically not too difficult to perform, guarantees a readily apparent improvement which will always satisfy the patient.

Skin thickness: Except for the skin extremes (very thick or very thin, which automatically change the classification to 'red light'), any other degree of skin thickness is acceptable in the green light category.

Frontal view: Green light noses often exhibit mild to moderate tip or pyramid problems (eg, a moderately wide tip, a mildly deviated pyramid, etc). These problems cannot, however, represent a major deformity (eg, major tip asymmetry), because such a single extreme finding will switch them to the red light category.

To recapitulate, the green light nose category is defined by the presence of a large hump, in the absence of very thick or very thin skin, as well as the absence of any major deformity of the nasal tip or pyramid.

Figure 3 shows examples of green light noses.

\section{Yellow light (Figure 1)}

Noses in the yellow light category are in between the green light and red light categories. They are reasonable rhinoplasty candidates, but not as ideal as the green light ones. The key characteristic of a yellow light nose is a mild to moderate hump in the profile view. This hump is not as large as that of a green light nose, but the dorsum is definitely not as straight or recessed as in a red light nose. Once again, the rest of the skin and frontal view (tip and pyramid) characteristics have no impact on the classification as long as they remain within the mild to moderate range.

Figure 4 shows an example of a yellow light nose.

\section{SUMMARY}

Rhinoplasties in the green light category are technically easy cases to execute, achieving impressive results and high patient satisfaction. Rhinoplasties in the red light category are technically challenging cases to execute, and often result in only subtle changes that are difficult for the patient to fully appreciate. Rhinoplasties falling in the yellow light category are somewhere in between, requiring more experience than the green light category noses, but are easier to correct than those in the red light category. Postoperatively 


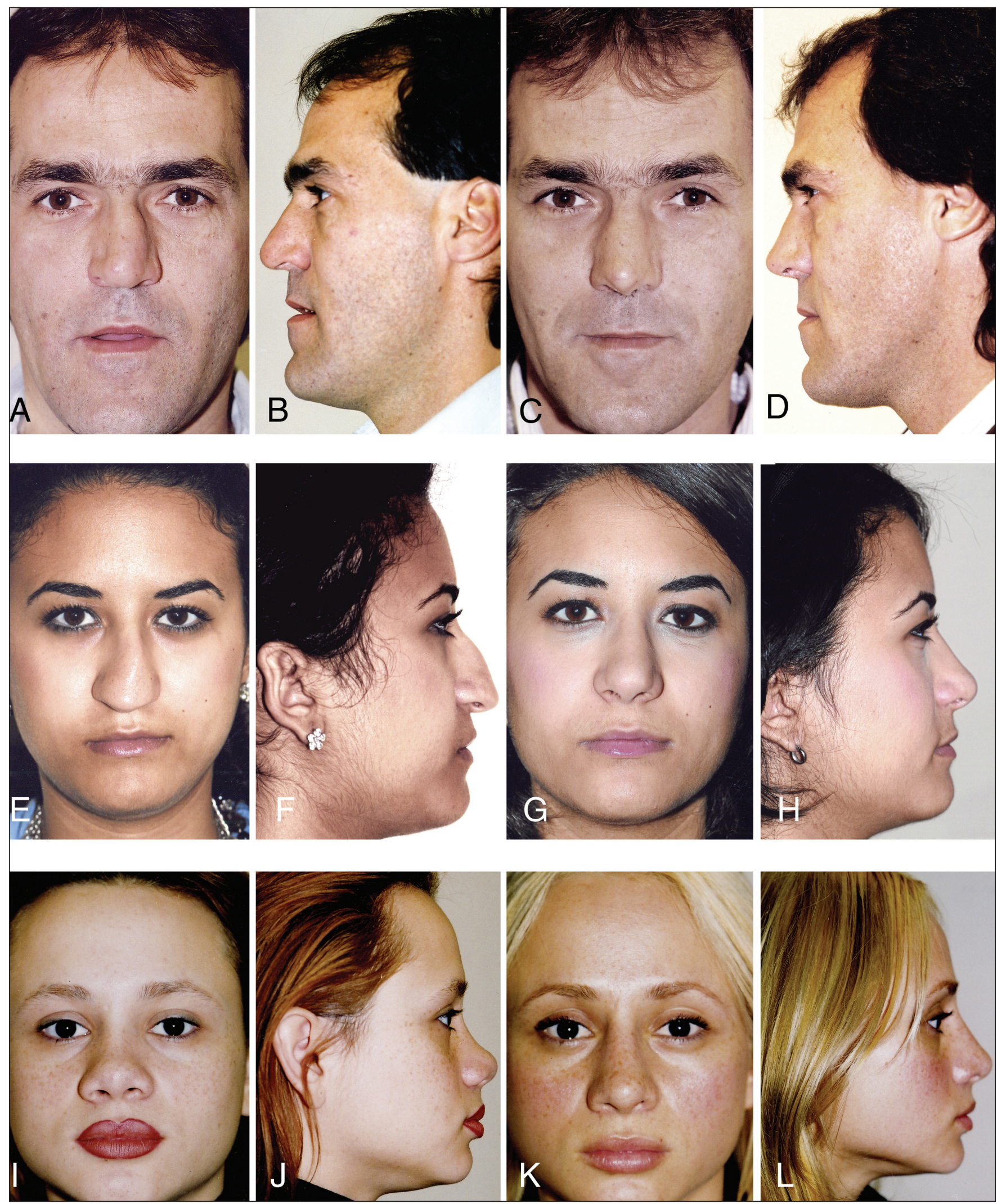

Figure 2) Examples of 'red light' noses. Patient 1: (A and B) Preoperative photographs of a 37-year-old man with a severe pyramid deformity, classifying it as a red light nose, even if he had a prominent hump (which he does not); (C and $\mathbf{D})$ postoperative results 11 months later. Patient 2: (E and F ) Preoperative photographs of a 18-year-old woman with a severe tip deformity and marked pyramid deviation, both classifying her into the red light category, in spite of her prominent hump; $(\mathrm{G}$ and $\mathrm{H})$ postoperative results six months later. Patient 3: (I and $\mathrm{J}$ ) Preoperative photographs of a 19-year-old woman with a saddle dorsum deformity; ( $\mathbf{K}$ and $\mathbf{L}$ ) postoperative results five years (62 months) later 

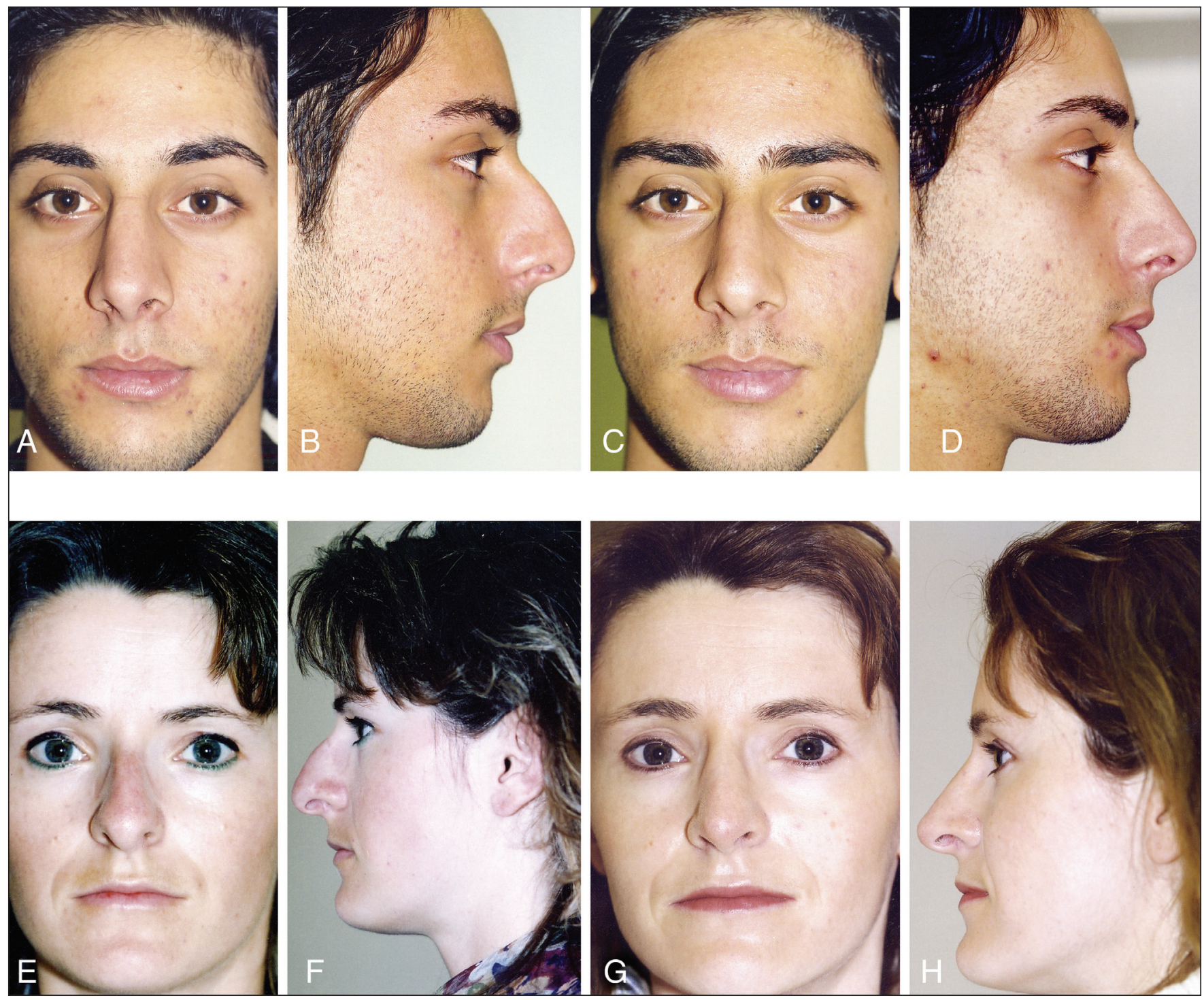

Figure 3) Examples of 'green light' noses. Patient 1: (A and B) Preoperative photographs of a 19-year-old man with a prominent dorsal hump, without any other significant nasal deformities; ( $\mathrm{C}$ and $\mathrm{D})$ postoperative results 12 months later. Patient 2: (E and F) Preoperative photographs of a 25-year-old woman with a significant hump and a mild tip deformity; $(\mathrm{G}$ and $\mathrm{H})$ postoperative results more than four years (52 months) later
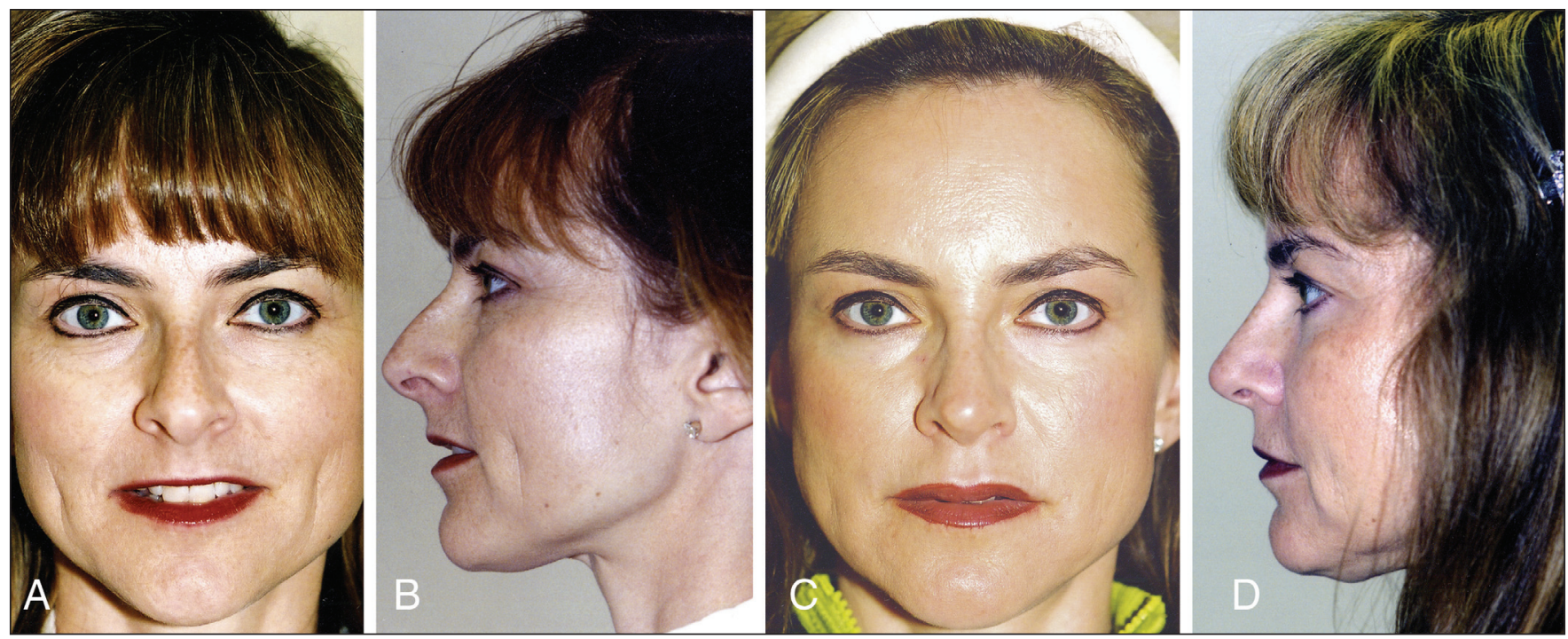

Figure 4) Example of a 'yellow light' nose, in between a 'green light' and a 'red light' nose, but closer to a green light one. A and B Preoperative pictures of a 54-year-old woman with a moderate hump and a mild tip problem; C and D Postoperative results 2.5 years (30 months) later 
TABLE 1

Summary of the four-step approach to the green I yellow I red light nose classification scheme

\begin{tabular}{|c|c|c|c|}
\hline Characteristic & Green light & Yellow light & Red light \\
\hline 1. Dorsum & Hump ++ & Hump + & $\begin{array}{l}\text { No hump } \\
\text { - Straight dorsum } \\
\text { - Saddle deformity }\end{array}$ \\
\hline 2. Skin & Average & Average & $\begin{array}{l}\text { Extreme skin } \\
\text { - Very thick } \\
\text { - Very thin }\end{array}$ \\
\hline 3. Tip & $\begin{array}{l}\text { Mild/moderate } \\
\text { problems }\end{array}$ & $\begin{array}{l}\text { Mild/moderate } \\
\text { problems }\end{array}$ & $\begin{array}{l}\text { Severe problems } \\
\text { - Severe recession } \\
\text { - Severe drooping } \\
\text { - Severe width }\end{array}$ \\
\hline 4. Pyramid & $\begin{array}{l}\text { Mild/moderate } \\
\text { problems }\end{array}$ & $\begin{array}{l}\text { Mild/moderate } \\
\text { problems }\end{array}$ & $\begin{array}{l}\text { Severe problems } \\
\text { - Very wide } \\
\text { - Very thin } \\
\text { - Deviation }\end{array}$ \\
\hline
\end{tabular}

Any single problem from the red light classification (eg, a saddle dorsum or an obvious pyramid deviation) automatically shifts the whole classification to the red light. ++ Prominent; + Mild to moderate

satisfactory results of yellow light category noses are more easily achieved than those of the red light noses.

\section{THE 'FOUR-STEP' PRACTICAL APPROACH TO RHINOPLASTY CLASSIFICATION}

For practical purposes, Table 1 summarizes the four-step approach to classify a rhinoplasty within a minute or less during consultation.

\section{The dorsum}

When assessing the nose preoperatively, the first area to consider is the dorsum in the profile view. The dorsum is a skeletal structure that is reasonably easy to correct. If a large dorsal hump is present, even with a moderate tip or pyramid deformity, the postoperative results are likely to be greatly appreciated by the patient. The larger the dorsal hump, the more obvious and satisfactory the result achieved. Therefore, a large dorsal hump on the profile view is the prime characteristic for a nose in the green light category.

A dorsal hump of medium prominence is also easily corrected. However, because the deformity is less obvious, the postoperative result is likely to be more subtle to the patient and less likely to provide as much gratification as in the case of a green light nose. This is the main reason why noses with small to medium dorsal humps are placed in the yellow light category.

Patients with no dorsal hump (ie, a straight or recessed dorsum on profile view) are placed in the red light category. In the absence of a dorsal hump, the main concern of the patient then has to deal with another problem, such as a recessed dorsum, a major nasal pyramid deformity (eg, a side-to-side deviation) or an important tip deformity (eg, a very wide tip), all of which are challenging to correct.

\section{The skin}

The second nasal feature to evaluate during preoperative examination is the skin. The thickness of the skin and subcutaneous tissue can have a significant impact on the surgical results. The average skin type, which is neither too thin nor too thick, shrinks and redrapes reasonably well after conservative bony or cartilaginous resection, in addition to effectively hiding most minor irregularities underneath it. Hence, the average skin type is placed into the green light and yellow light categories.

Very thin skin has the advantage of more postoperative shrinkage, better redraping, less postoperative edema and faster recovery than the average skin. However, it fails to camouflage asymmetries of the underlying bony and cartilaginous framework.

On the other hand, thick skin contracts poorly, which limits the extent of possible overall nasal reduction. As well, thick skin develops a greater amount of postoperative edema than average skin, and may even become thicker postoperatively (causing a pollybeak deformity) due to increased subcutaneous scar formation.

Therefore, based on the caveats discussed above, a nose covered by an extreme skin (either too thin or too thick) is classified in the red light category.

\section{3. and 4. The tip and pyramid}

Finally, correction of nasal tip deformities or nasal pyramid deviations represents the most technically demanding aspect of rhinoplasty. The complex anatomy, the inherent dynamic forces to be analyzed and manipulated, the delicate support mechanisms that must be respected or reconstructed, and the overlying skin envelope can all have a significant influence on the final result. Hence, any nose presenting a significant tip or pyramid deformity is classified in the red light category.

\section{CONCLUSION}

We propose a simple and systematic approach to nasal analysis, allowing the rhinoplastic surgeon, especially the novice or occasional surgeon, to estimate the degree of technical difficulty associated with a specific rhinoplasty, as well as the expected patient's satisfaction with its result.

Green light noses are reasonably easy to execute and are most likely to yield significant esthetic improvement with high patient satisfaction. Noses in this category represent the ideal patients for a surgeon who is in the process of building a rhinoplastic practice.

On the other hand, noses that are categorized into the red light category should probably be left to a more experienced surgeon. The results achieved in these cases tend to be far from overwhelming to the patient, even when successful surgery is performed, and despite the high degree of technical expertise required to correct such deformities.

Finally, noses falling into the yellow light category should be operated at the surgeon's discretion, based on his or her level of comfort and confidence.

ACKNOWLEDGEMENTS: The authors express their thanks to Ildico Horvath, medical artist, Montreal General Hospital, for her assistance in preparing the artwork; Minerva Khalife, clinical assistant, for her photographic contributions; Maria Iancu for the typing and editing; Barbara Armbruster, MA for the final editing; and Stephanie Luetticken, MBA, for organizing the manuscript submission. 


\section{REFERENCES}

1. Macgregor FC, Schaffner B. Screening patients for nasal plastic operations; sociologic and psychiatric considerations. Psychosom Med. 1950;12:277-91.

2. Phillips KA. Body dysmorphic disorder: The distress of imagined ugliness. Am J Psychiatry 1991;148:1138-49.

3. Rees TD. Selection of patients. In: Rees, TD ed. Aesthetic Plastic Surgery. Philadelphia: WB Saunders, 1980.

4. Housman SB. Psychological aspects of plastic surgery. In: McCarthy JG, ed. Plastic Surgery. Philadelphia: WB Saunders, 1990.

5. Hill G, Silver AG. Psychodynamic and esthetic motivations for plastic surgery. Psychosom Med 1950;12:345-55.

6. Goin JM, Goin MK. Changing the Body: Psychological Effects of Plastic Surgery. Baltimore: Williams \& Wilkins, 1981.

7. Tardy ME. Surgical Anatomy of the Nose. New York: Raven Press, 1990.

8. Tardy ME. Rhinoplasty: The Art and the Science. Philadelphia: Saunders, 1996.

9. Sheen JH. Aesthetic Rhinoplasty. St Louis: Mosby, 1978.

10. Rees TD, Baker DC, Tabbal N. Rhinoplasty Problems and Controversies. St Louis: Mosby, 1988:283.

11. Sheen JH, Sheen A. Aesthetic Rhinoplasty, 2nd edn. St Louis: Mosby, 1987:1,234.

12. Anderson JR. A reasoned approach to nasal base surgery. Arch Otolaryngol 1984;110:349-58.
13. Tardy ME Jr, Patt BS, Walter MA. Transdomal suture refinement of the nasal tip: Long-term outcomes. Facial Plast Surg 1993;9:275-84.

14. Toriumi DM, Tardy ME. Cartilage suturing techniques for correction of nasal tip deformities. Op Tech Otolaryngol Head Neck Surg 1995;6:265-73.

15. Tardy ME, Toriumi DM. Principles of rhinoplasty. In: Papel ID, Nacklas NE, eds. Facial Plastic and Reconstructive Surgery. St Louis: Mosby Year Book, 1991:278-94.

16. Tardy ME Jr, Cheng EY, Jernstrom V. Misadventures in nasal tip surgery. Otolaryngol Clin North Am 1987;20:797-823.

17. Bernstein L. Esthetics in rhinoplasty. Otolaryngol Clin North Am 1975;8:705-15.

18. Farkas LG, Kolar JC, Munro IR. Geography of the nose: A morphometric study. Aesthetic Plast Surg 1986;10:191-223.

19. Meyer R. Secondary and Functional Rhinoplasty: The Difficult Nose. Orlando: Grune \& Stratton, 1988:93.

20. Anderson JR. Straightening the crooked nose. Trans Am Acad Ophthalmol Otolaryngol 1972;76:938-45.

21. Roofe SB, Murakami CS. Treatment of the posttraumatic and postrhinoplasty crooked nose. Facial Plast Surg Clin North Am 2006;14:279-89.

22. McKinney P, Johnson P, Wollock J. Anatomy of the nasal hump. Plast Reconstr Surg 1986;77:404-5. 